\title{
SIMULATION OF TWO AREA POWER SYSTEM USING SOFT COMPUTING TECHNIQUES IN A DEREGULATED POWER SYSTEM
}

\author{
Akshay Kumar Khaiwal ${ }^{1}$, Vinod Kumar Giri ${ }^{2}$ \\ Department Of Electrical Engineering, M.M.M. University of Technology, Gorakhpur, U.P., India ${ }^{1,2}$
}

\begin{abstract}
In recent years, power quality and efficiency are major attributes for a power industry especially after deregulation laws have been adopted. This paper presents a comparative view of the Soft Computing techniques i.e., Fuzzy Logic Control (FLC) and Genetic Algorithm (GA) based Fuzzy PID Controllers have been used in Two Area Power System for Load Frequency Control (LFC) under deregulation. Two Area Power System with two GENCOS and two DISCOS in each area have been taken for analysis. Load Frequency Control of the two areas of power system and tie-line power flow are the parameters observed by simulating the model. During the sudden load changes the load frequency control is the major issue i.e., to maintain the real frequency and the desired power output in interconnected power system and to control the change in tie-line power between two control areas. The two area power system model has been analysed under time domain parameters which shows the requirements for load frequency control under Genetic Algorithm (GA) based Fuzzy PID controller improves as compared to Fuzzy Logic Control Technique.
\end{abstract}

Index Terms: Load Frequency Control (LFC), Two Area Power System, Deregulation, Fuzzy Logic control (FLC), Genetic Algorithm (GA), Fuzzy-PID controller, MATLAB/SIMULINK.

\section{INTRODUCTION}

If the load on the system is increased, the turbine speed drops before the governor so as to adjust input of the steam to the new load. Speed of the rotor can be maintained constant by adding an integrator. The integral unit monitors the average error over the period of time and will overcome the offset.

As the system load changes continuously, the generation is adjusted automatically to restore its frequency to nominal value. This scheme is known as Load Frequency Control (LFC) (Introduction \& Scenario, 2013). This is one of the most important power system control problems in a multi are-power system (Daneshfar et al., 2011).

The frequency of the power systems depends on the active power balance. Deviation in the frequency of the power system reflects the change in active power demand at any point in the system. Hence change in system frequency can be used as an indicator for imbalance in the power generation and the demand. The real power of the system depends on the prime mover's mechanical power output.

The prime mover has been selected based on the type of generating unit. It may be a steam, gas, hydro turbine or a diesel engine. In a steam or hydro turbine, valves must regulate the amount of steam or water flowing into the turbine. This has been done to match the real power demand. A linear model of the system is both primary and Secondary LFC loop model:

(i)PRIMARY CONTROL: Control of frequency by action of governors.

(ii)SECONDARY CONTROL: Loading of different plants is changed on instructions of central load. Dispatchers in order to attain $\Delta \mathrm{f}=0$. (maximum permissible variation in supply frequency is $\pm 0.5 \mathrm{~Hz}$ ).

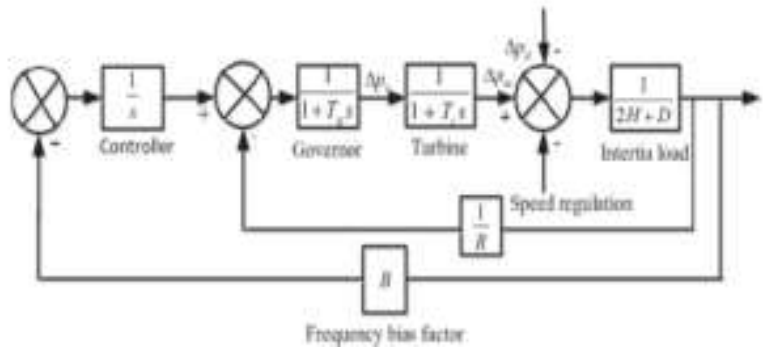

Figure 1: Load frequency Model 
International Journal of Innovative Research in

Electrical, Electronics, Instrumentation and Control Engineering

Vol. 9, Issue 6, June 2021

DOI 10.17148/IJIREEICE.2021.9605

Engendering the change in power system structure by including the private participants and by increasing the customer role in the pool electricity market (Bevrani et al., 2004) (Ph et al., 2018). The transition of the power sector from regulated to deregulated structure includes many positive and negative outcomes.

Deregulation is change in the rules and regulations that govern the operation of any system.

In any type of market, technological and economic reforms are necessary in order to increase the quality of the product, efficiency of the system and meet consumer needs.(M. J. Vahid-Pakdel, 2021) Thus, increase the production as well as profit. Factors that led to deregulation are

(a) Change in Power Generation Technologies

(b) Worldwide Trends Towards Liberalization of Infrastructure Industries.

(C) Development in Computerized Control and Data Communication.

\section{II.TWO AREA POWER SYSTEM}

Deregulated system contains the GENCOS, DISCOS, TRANSCOS and ISO which are generating, distribution and transmission companies along with independent service operators respectively (Pourmousavi et al., 2016). The two area power system with two GENCOS and two DISCOS in each area are considered for this model(Nayak et al., 2019).

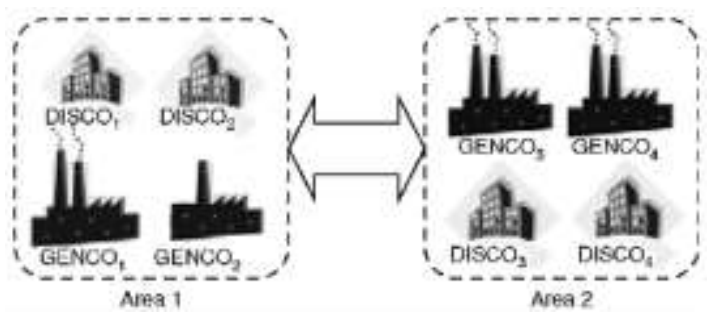

Figure 2: Multi Area Power system

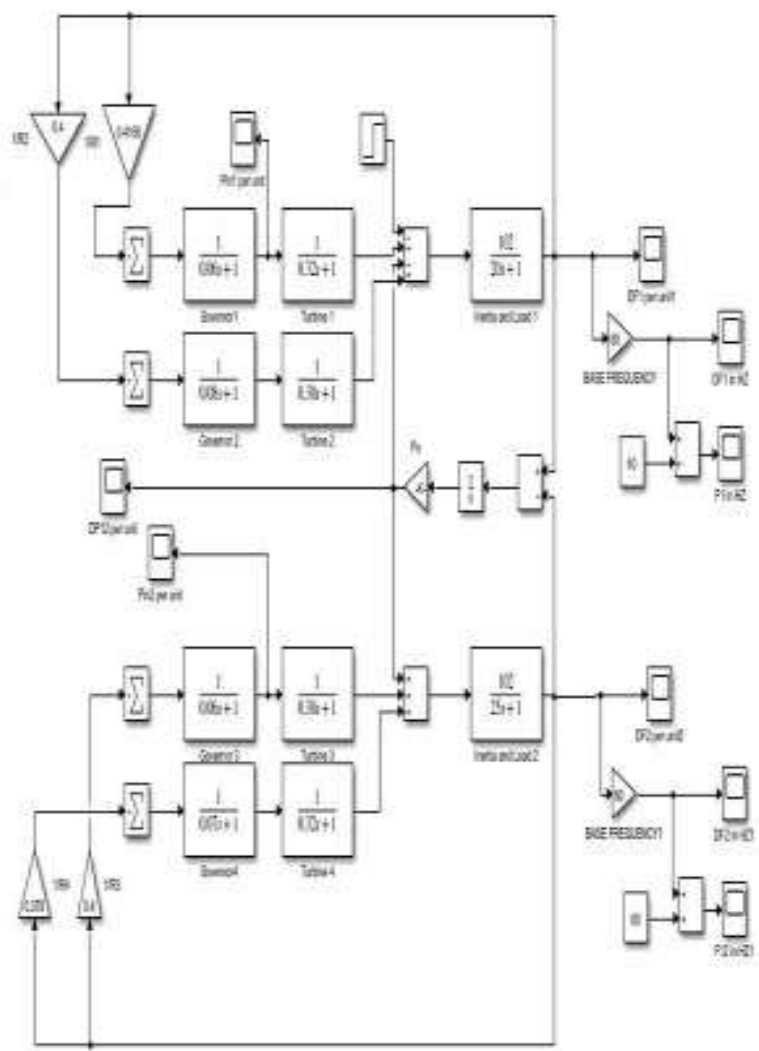

Figure 3: Two Area Power System Simulink Model

DPM "Disco Participation Matrix" gives the interactive relation between the DISCO and GENCO. The number of each gives the rows and column respectively. The DPM is subjected to work under the order of independent service operators (ISO). The sum of all the columns in DPM is equal to 1. 
International Journal of Innovative Research in Electrical, Electronics, Instrumentation and Control Engineering

Vol. 9, Issue 6, June 2021

DOI 10.17148/IJIREEICE.2021.9605

Table 1: DPM Table

\begin{tabular}{|l|l|l|l|}
\hline Cpf11 & Cpf12 & Cpf13 & Cpf14 \\
\hline Cpf21 & Cpf22 & Cpf23 & Cpf24 \\
\hline Cpf31 & Cpf32 & Cpf33 & Cpf34 \\
\hline Cpf41 & Cpf42 & Cpf43 & Cpf44 \\
\hline
\end{tabular}

The requirements of the system are met by DISCO that area and GENCO maintain ACE in proportion to their contracts (Lekshmi \& Balamurugan, 2017). For any mismatch between actual and contracted demands the results in frequency deviation that will drive AGC to re- dispatch GENCOs according to Area participation factor (apf) $\sum$ apfij=1.

\section{PARAMETERS}

The GENCO, Control area, DISCO participation matrix and area participation parameters have been tabled below:

GENCO Parameters

\begin{tabular}{|c|c|c|c|c|}
\hline $\begin{array}{c}\text { GENCO } \\
\text { Parameters }\end{array}$ & \multicolumn{2}{|c|}{ AREA 1 } & \multicolumn{2}{c|}{ AREA 2 } \\
\hline & $\begin{array}{c}\text { GENCO } \\
1\end{array}$ & $\begin{array}{c}\text { GENCO } \\
2\end{array}$ & $\begin{array}{c}\text { GENCO } \\
3\end{array}$ & $\begin{array}{c}\text { GENCO } \\
3\end{array}$ \\
\hline $\operatorname{Tt}(\mathrm{s})$ & 0.32 & 0.3 & 0.3 & 0.32 \\
\hline $\mathrm{Tg}(\mathrm{s})$ & 0.06 & 0.08 & 0.06 & 0.07 \\
\hline $\mathrm{R}(\mathrm{hz} / \mathrm{pu})$ & 2.4 & 2.5 & 2.5 & 2.7 \\
\hline
\end{tabular}

Control Area Parameters

\begin{tabular}{|c|c|c|}
\hline $\begin{array}{c}\text { Control Area } \\
\text { Parameters }\end{array}$ & AREA 1 & AREA 2 \\
\hline $\mathrm{Kp}(\mathrm{pu} / \mathrm{hz})$ & 102 & 102 \\
\hline $\mathrm{Tp}(\mathrm{s})$ & 20 & 25 \\
\hline $\mathrm{B}(\mathrm{pu} / \mathrm{hz})$ & 0.425 & 0.396 \\
\hline $\mathrm{Ki}$ & 0.7 & 0.25 \\
\hline $\mathrm{T} 12(\mathrm{pu} / \mathrm{hz})$ & \multicolumn{2}{|c|}{0.245} \\
\hline
\end{tabular}

The cpf's from DISCO Participation Matrix (DPM) is given by: DP Matrix

\begin{tabular}{|c|c|c|c|}
\hline 0.5 & 0.25 & 0 & 0.3 \\
\hline 0.2 & 0.25 & 0 & 0 \\
\hline 0 & 0.25 & 1 & 0.7 \\
\hline 0.3 & 0.25 & 0 & 0 \\
\hline \multicolumn{4}{|c}{ Area Participation Factors } \\
\hline
\end{tabular}

\begin{tabular}{|c|c|c|}
\hline APF's & AREA 1 & AREA 2 \\
\hline Apf 1 & 0.75 & 0.5 \\
\hline Apf 2 & 0.25 & 0.5 \\
\hline
\end{tabular}


International Journal of Innovative Research in Electrical, Electronics, Instrumentation and Control Engineering

Vol. 9, Issue 6, June 2021

DOI 10.17148/IJIREEICE.2021.9605

\section{FUZZY LOGIC CONTROL AND GENETIC ALGORITHM}

Soft computing techniques are the most innovative methods to use in an interactive world with changes and possibility of producing probable events by computing the system. Fuzzy Logic Control (FLC)

(Tur, n.d.) and Genetic Algorithm (GA) are such techniques.

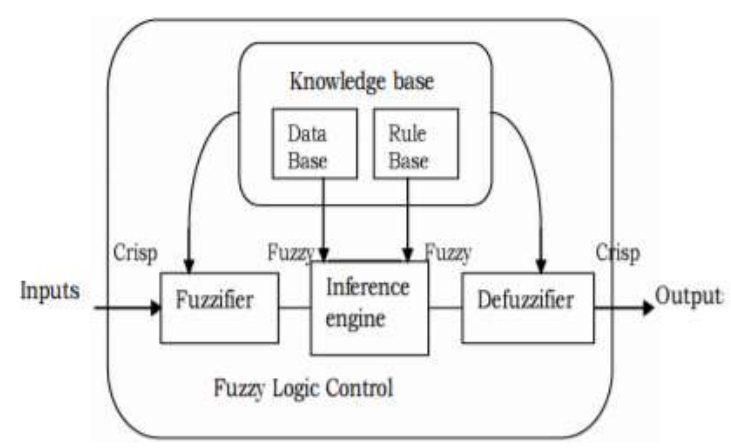

Figure 4: Schematic Fuzzy Building Block

FLC with MAMDANI approach is used in the model. During fuzzification process input data i.e., fuzzy variable is analysed as per the user-defined charts called membership functions. The controller takes the input data from 0 to 1 based on how well it fits into each membership function. Mamdani approach uses the centre of gravity technique [5].(Singh \& Sathans, 2016) for de-fuzzification process to calculate the output (Chandrashekar \& Jayapal, 2013).

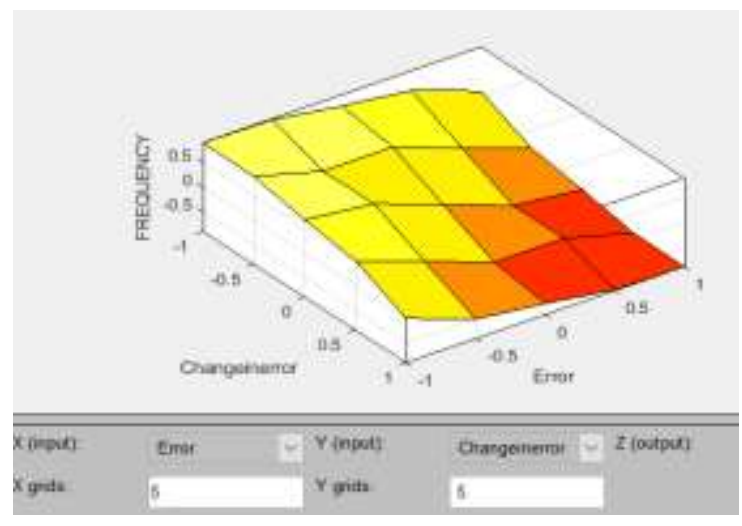

Figure 5: Surface Area View

IF-THEN principle of fuzzy rule base is used which is a form based categorised from desired membership functions. The rule says:

If $\mathrm{x}$ is $\mathrm{A} 1$ Then $\mathrm{y}$ is

Where, A1 and B2 are linguistic variables defined by fuzzy sets on the ranges (i.e. universe of discourse) $\mathrm{X}$ and $\mathrm{Y}$ respectively. The If-part of the rule ' $\mathrm{x}$ is A1' is called the antecedent or premise and the Then-part of the rule ' $y$ is B2' is called the consequent.

Table 2: Rule Base Of Fuzzy Model

\begin{tabular}{|l|l|l|l|l|l|l|l|}
\hline ACE/ $\triangle \mathrm{ACE}$ & HN & MN & LN & ZE & LP & MP & HP \\
\hline HN & HP & HP & HP & MP & MP & LP & ZE \\
\hline MN & HP & HP & MP & MP & LP & ZE & LN \\
\hline LN & HP & MP & MP & LP & ZE & LN & LN \\
\hline
\end{tabular}


International Journal of Innovative Research in Electrical, Electronics, Instrumentation and Control Engineering

Vol. 9, Issue 6, June 2021

DOI 10.17148/IJIREEICE.2021.9605

\begin{tabular}{|l|l|l|l|l|l|l|l|}
\hline ZE & MP & MP & LP & ZE & LN & LN & MN \\
\hline LP & MP & LP & ZE & LN & MN & MN & HN \\
\hline MP & LP & ZE & LN & MN & MN & MN & HN \\
\hline HP & ZE & LN & LN & MN & MN & HN & HN \\
\hline
\end{tabular}

(HN: High Negative, MN: Medium Negative,

LN: Low Negative, Z: Zero, HP: High Positive, MP: Medium Positive, LP: Low Positive)

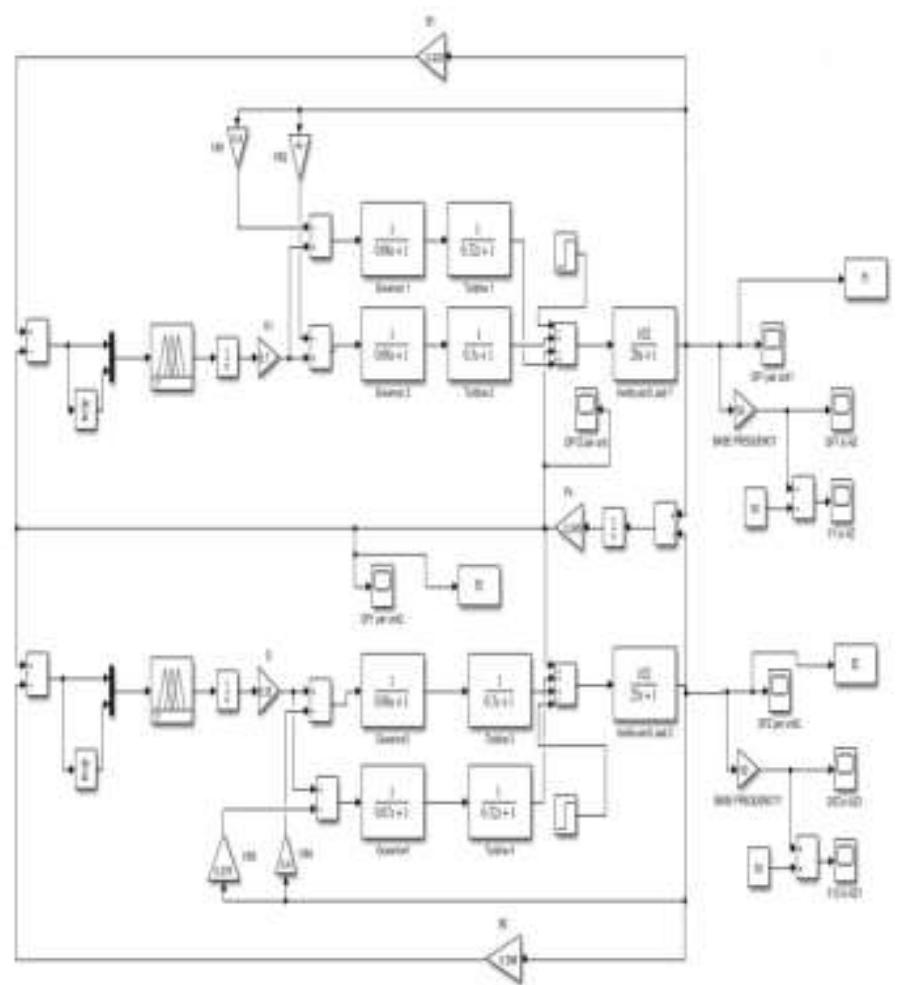

Figure 6: Two Area Power System with FLC Control

\section{GA OPTIMIZED FUZZY-PID CONTROLLER}

Genetic Algorithm (GA) is a field of search heuristic in soft computing techniques which imitates the natural selection process in order to optimise more complex mathematical modelling equations. Genetic Algorithm is based on iterative process to carry out on various defined parameters so as to find the best possible of outcomes for the parameters involved.

The paper implements a Fuzzy-PID controller (Chaiyatham et al., 2009) which is GA tuned for optimising the controller parameters in accordance with the given specifications.

The classical proportional-integral-derivative (PID) controller has been mostly adopted by researchers for AGC control purpose (Tabassum \& Rana, 2020).

The values of gains for proportional, integration and derivative factors are calculated by GA based approach. For both the area same approach is defined in the system to iterate the values for $\mathrm{Kp}, \mathrm{Ki}$ and $\mathrm{Kd}$. Performance indices such as ITAE, IAE, ISE and ITSE (Krishnan \& Vijaya Chandrakala, 2019). are used to analyse the "fitness factor" (Method, 2014). 
International Journal of Innovative Research in

\section{Electrical, Electronics, Instrumentation and Control Engineering}

Vol. 9, Issue 6, June 2021

DOI 10.17148/IJIREEICE.2021.9605

The lowest value of the parameter is considered and controller gains are accordingly calibrated with genetic algorithm approach. For this system ITSE value of performance indices is found higher than other indices values.

Scope values for ITSE indices:

(i) For Area 1: 4.6219 and

(ii)For Area 2: 3.697

Scope values for ISE indices:

(i)For Area 1: 1.345 and

(ii)For Area 2: 1.697

Scope values for ISE indices:

(i)For Area 1: 1.544 and

(ii)For Area 2: 0.998

The main aim is to get an overshoot within the specified range and to minimise the settling time. The controller is then compared with Fuzzy logic control approach and the transient and steady-state response are analysed These values are confirmed by the results in Simulink model.

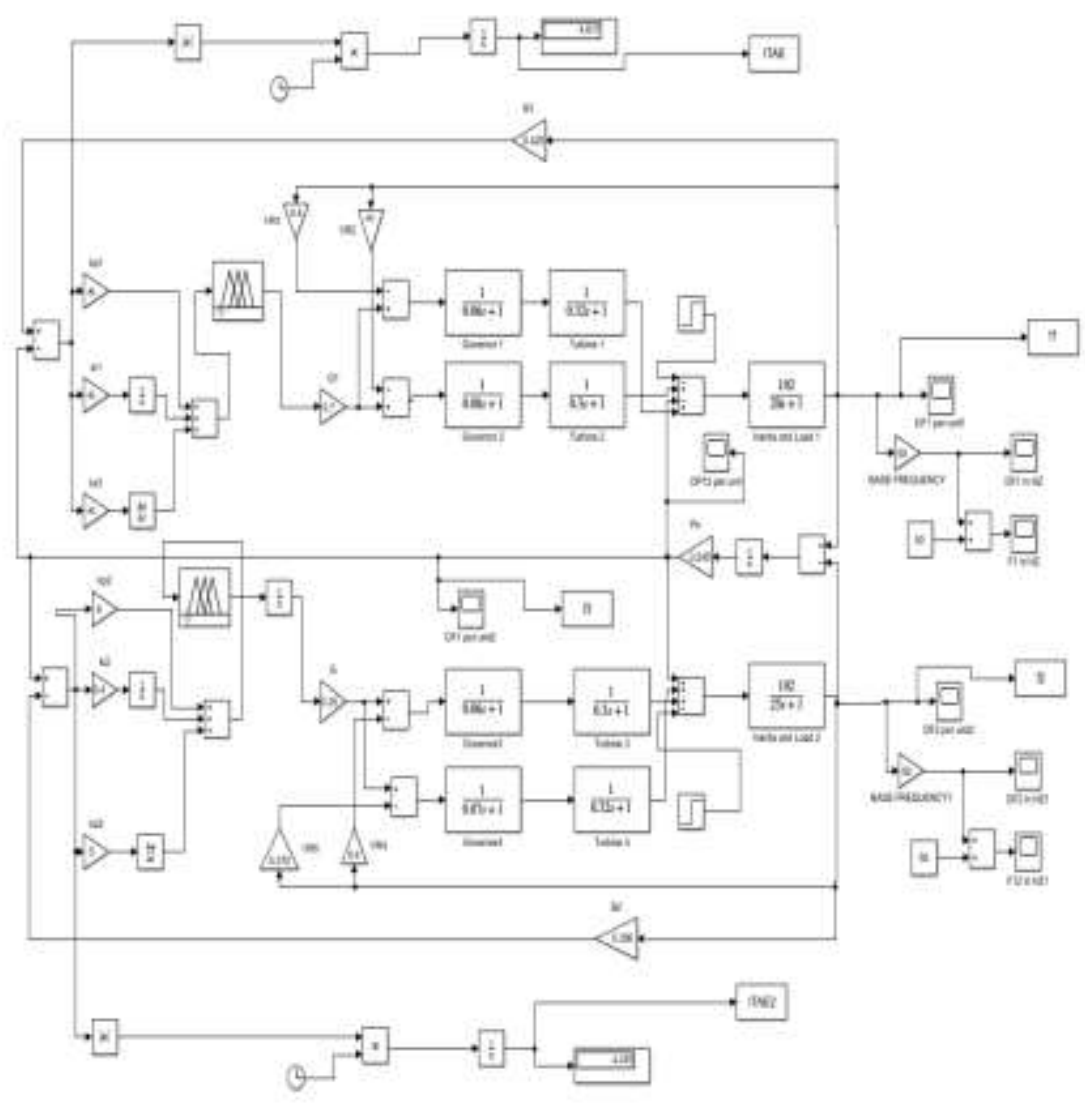

Figure 7: GA Optimized Fuzzy-PID Controller

The controller gains parameters for both PID controllers of area 1 and area 2 are shown in Table 3.

MATLAB command line is used to optimize the values are:

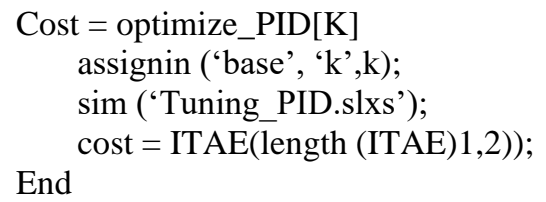


International Journal of Innovative Research in Electrical, Electronics, Instrumentation and Control Engineering

Vol. 9, Issue 6, June 2021

DOI 10.17148/IJIREEICE.2021.9605

Table 3: Controller Gains in Area 1 And 2

\begin{tabular}{|l|l|l|l|}
\hline CONTROLLER & $\mathrm{Kp}$ & $\mathrm{Ki}$ & $\mathrm{Kd}$ \\
\hline AREA 1 & 6.32 & 0.356 & 5.08 \\
\hline AREA 2 & 5.98 & 0.322 & 5.01 \\
\hline
\end{tabular}

\section{SIMULATION RESULTS}

The simulation results have been taken for frequency deviation in area 1, area 2 and tie-line power flow for the situation when a sudden load change of 100MW in area 1 and 150MW in area 2 . The DISCOS demands the power 0.1 $p u$ and $0.15 p u$ from other GENCOS as per the entries in DPM and these GENCOS participate by desired area participation factor. Results of the simulation have been shown for change in frequency deviation of area 1 in figure 8 , change in frequency deviation of area 2 in figure 9 and change in tie-line power in figure 10.
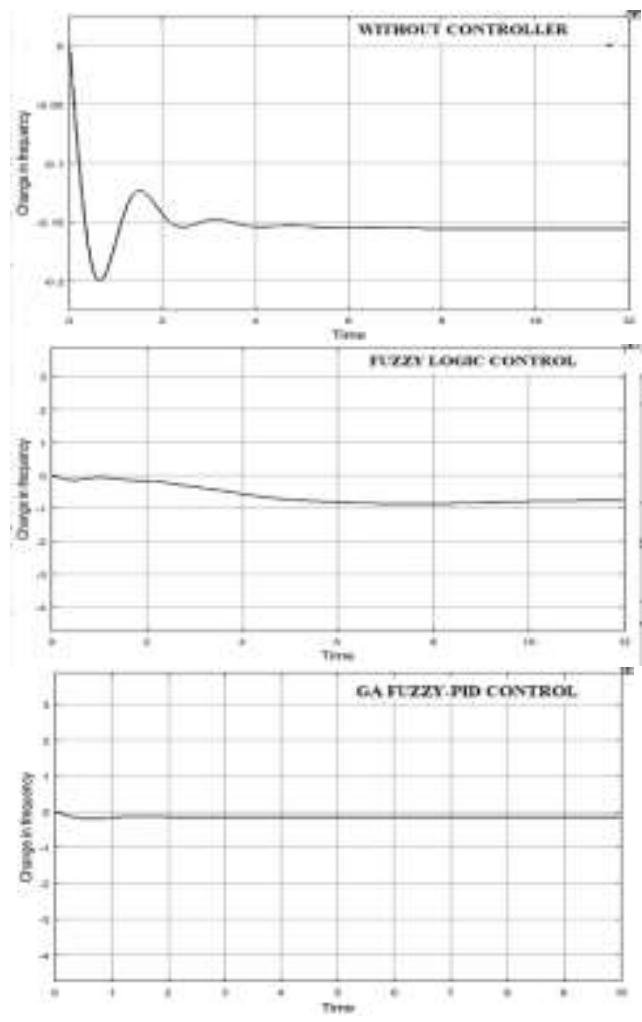

Figure 8: Frequency Deviation $(\mathrm{rad} / \mathrm{sec})$ in Area 1

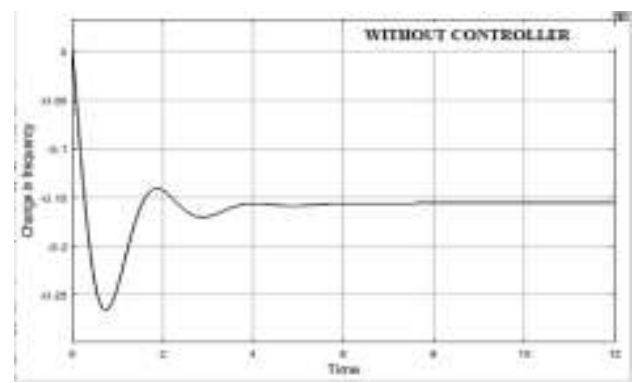


International Journal of Innovative Research in Electrical, Electronics, Instrumentation and Control Engineering

Vol. 9, Issue 6, June 2021

DOI 10.17148/IJIREEICE.2021.9605
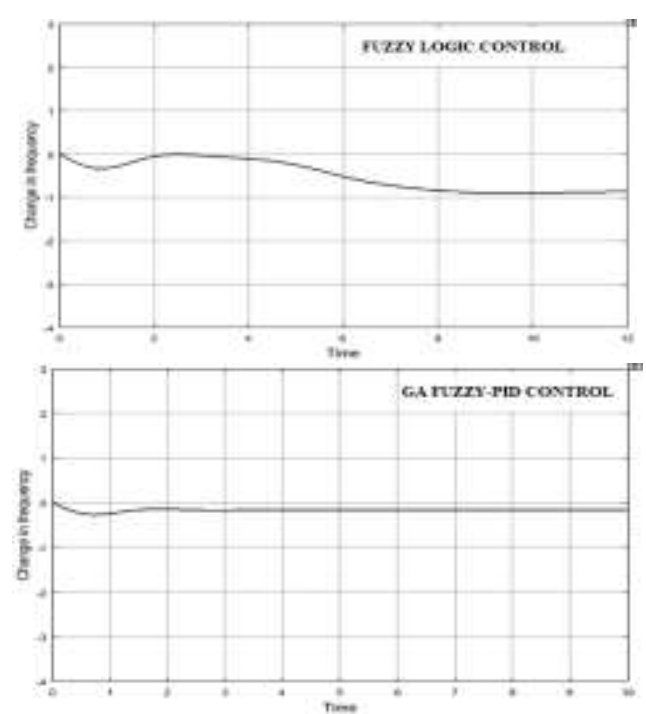

Figure 9: Frequency Deviation (rad/sec) In Area 2
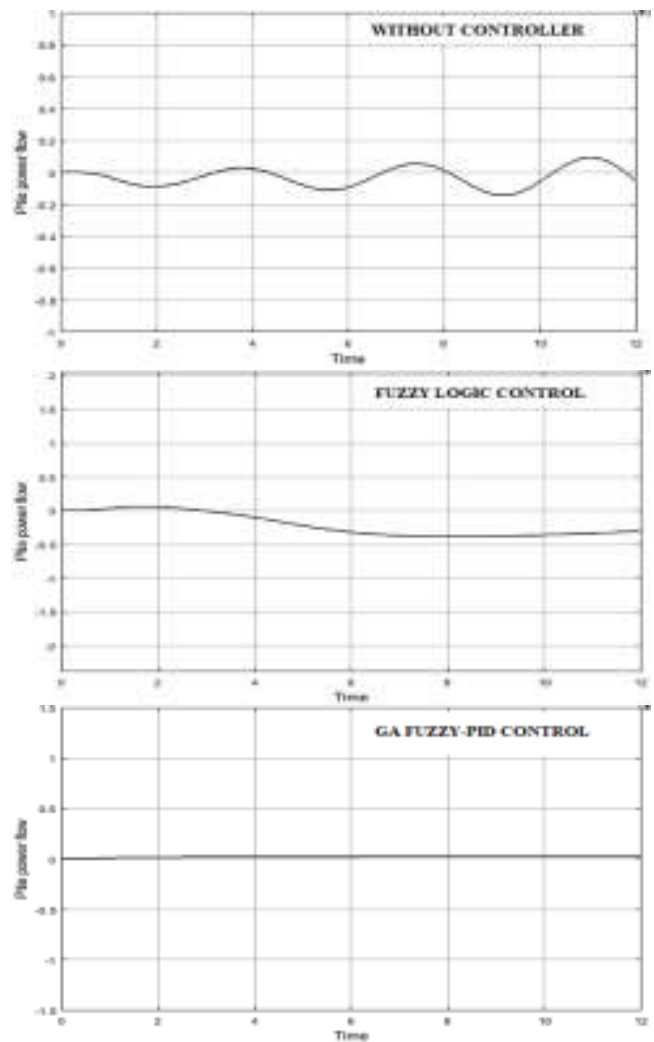

Figure 10: P-tie Power Flow ( $р и \mathrm{MW})$

Table 4: Performance Parameters ( Tss- settling time, Mp- peak overshoot ) 
International Journal of Innovative Research in Electrical, Electronics, Instrumentation and Control Engineering

Vol. 9, Issue 6, June 2021

DOI 10.17148/IJIREEICE.2021.9605

\begin{tabular}{|c|c|c|c|c|c|c|}
\hline & \multicolumn{2}{|c|}{$\begin{array}{c}\text { Without } \\
\text { Controller }\end{array}$} & \multicolumn{2}{c|}{$\begin{array}{c}\text { Fuzzy Logic } \\
\text { Control }\end{array}$} & \multicolumn{2}{c|}{$\begin{array}{c}\text { GA Fuzzy-PID } \\
\text { Control }\end{array}$} \\
\cline { 2 - 7 } & Tss & $\mathrm{Mp}$ & Tss & $\mathrm{Mp}$ & Tss & $\mathrm{Mp}$ \\
\hline $\begin{array}{c}\text { Frequency } \\
\text { Deviation AREA } \\
1\end{array}$ & 9.2 & 0.20 & 6.8 & 0.13 & 1.9 & 0.02 \\
\hline $\begin{array}{c}\text { Frequency } \\
\text { Deviation AREA } \\
2\end{array}$ & 8.5 & 0.28 & 7.8 & 0.79 & 2.8 & 0.20 \\
\hline $\begin{array}{c}\text { P-tie Power } \\
\text { Deviation }\end{array}$ & 21 & 0.15 & 11 & 0.35 & 3 & 0.04 \\
\hline
\end{tabular}

\section{CONCLUSIONS}

The paper demonstrates two soft computing techniques used for Load Frequency Control of a two area power system in deregulated conditions. Both the techniques have been separately simulated in MATLAB under the desired conditions so as to compare the results of the deviation in frequencies in area 1,2 and change in tie line power demands. Analysis of the computing techniques demonstrates good results and use of these methods reduces the peak deviation of frequencies i.e. more reduction of settling time in GA optimized Fuzzy-PID controller than in the case of Fuzzy logic control technique. The system can further be used on a larger system by using different combinations of mathematical expressions which can contribute and decide the precise contact participation matrix values for the DISCOS and GENCOS.

\section{REFRENCES}

[1]. Bevrani, H., Member, S., Mitani, Y., \& Tsuji, K. (2004). Robust Decentralized LFC Design In a Deregulated Environment. April, $326-331$.

[2]. Chaiyatham, T., Ngamroo, I., Pothiya, S., \& Vachirasricirikul, S. (2009). Design of Optimal Fuzzy Logic-PID Controller using Bee Colony Optimization for Frequency Control in An Isolated Wind-Diesel System. 1, 5-8.

[3]. Chandrashekar, M. J., \& Jayapal, R. (2013). Design and comparison of I, PI, PID and Fuzzy logic controller on AGC deregulated power system with HVDC link. 2013 International Conference on Circuits, Controls and Communications, CCUBE 2013. https://doi.org/10.1109/CCUBE.2013.6718564

[4]. Daneshfar, F., Bevrani, H., \& Mansoori, F. (2011). Bayesian networks design of load-frequency control based on GA. Proceedings - 2011 2nd International Conference on Control, Instrumentation and Automation, ICCIA 2011, 315-319. https://doi.org/10.1109/ICCIAutom.2011.6356676

[5]. Introduction, P., \& Scenario, P. (2013). Review of Load Frequency Control Methods. 2013 International Conference on Circuits, Controls and Communications, CCUBE 2013IEEE, 1-5.

[6]. Krishnan, A. R., \& Vijaya Chandrakala, K. R. M. (2019). Genetic algorithm tuned load frequency controller for hydro plant integrated with AC microgrid. 2019 International Conference on Intelligent Computing and Control Systems, ICCS $2019, \quad$ Iciccs, $491-494$. https://doi.org/10.1109/ICCS45141.2019.9065875

[7]. Lekshmi, R. R., \& Balamurugan, S. (2017). Area and economic participation factor calculation of GENCOs in a multi area competitive power system. Proceedings of IEEE International Conference on Circuit, Power and Computing Technologies, ICCPCT 2017. https://doi.org/10.1109/ICCPCT.2017.8074359

[8]. M. J. Vahid-Pakdel, S. (2021). Modeling Noncooperative Game of G .... 8654689.

[9]. Method, A. Z. N. (2014). Application of Ant Colony Algorithm for calculation and analysis of Performance Indices for adaptive control system. November, 466-471.

[10]. Nayak, P. C., Bisoi, S., Prusty, R. C., \& Panda, S. (2019). Performance analysis of PDF+(1+PI) controller for load frequency control of the multi microgrid system using genetic algorithm. Proceedings - 2019 International Conference on Information Technology, ICIT 2019 , $448-453$. https://doi.org/10.1109/ICIT48102.2019.00085

[11]. Ph, D. C. G., Engineering, E., Bilaspur, C. G., Engineering, E., \& Shegaon, M. S. (2018). RESEARCH ARTICLE RESTRUCTURING AND DEREGULATION OF POWER SYSTEM -A REVIEW 1, * Pawan C. Tapre, 2 Dr. Dharmendra kumar Singh and 3 Dr. Sudhir Paraskar.

[12]. Pourmousavi, S. A., Behrangrad, M., Nehrir, M. H., \& Ardakani, A. J. (2016). LFC model for multi-area power systems considering dynamic demand response. Proceedings of the IEEE Power Engineering Society Transmission and Distribution Conference, $2016-J u l y$, 1-5. https://doi.org/10.1109/TDC.2016.7519908

[13]. Singh, A., \& Sathans. (2016). GA optimized PID controller for frequency regulation in standalone AC microgrid. India International Conference on Power Electronics, IICPE, 2016-Novem. https://doi.org/10.1109/IICPE.2016.8079367

[14]. Tabassum, F., \& Rana, M. S. (2020). Robust Control of Frequency for Multi-Area Power System. 2020 IEEE Region 10 Symposium, TENSYMP 2020, June, 86-89. https://doi.org/10.1109/TENSYMP50017.2020.9230682

[15]. Tur, M. R. (n.d.). Load Frequency Control of Two Area Interconnected Power System Using Fuzzy Logic Control and PID Controller. 5, 1-6. 